\title{
Effects of hydrogen sulfide on hemodynamics, inflammatory response and oxidative stress during resuscitated hemorrhagic shock in rats
}

Frédérique Ganster ${ }^{1,2,6}$, Mélanie Burban¹, Mathilde de la Bourdonnaye ${ }^{1}$, Lionel Fizanne ${ }^{1}$, Olivier Douay¹, Laurent Loufrani ${ }^{3}$, Alain Mercat ${ }^{1,2}$, Paul Calès ${ }^{1,2}$, Peter Radermacher ${ }^{4}$, Daniel Henrion ${ }^{3}$, Pierre Asfar ${ }^{1,2^{*}}$, Ferhat Meziani ${ }^{2,5,6}$

\begin{abstract}
Introduction: Hydrogen sulfide $\left(\mathrm{H}_{2} \mathrm{~S}\right)$ has been shown to improve survival in rodent models of lethal hemorrhage. Conversely, other authors have reported that inhibition of endogenous $\mathrm{H}_{2} \mathrm{~S}$ production improves hemodynamics and reduces organ injury after hemorrhagic shock. Since all of these data originate from unresuscitated models and/or the use of a pre-treatment design, we therefore tested the hypothesis that the $\mathrm{H}_{2} \mathrm{~S}$ donor, sodium hydrosulfide (NaHS), may improve hemodynamics in resuscitated hemorrhagic shock and attenuate oxidative and nitrosative stresses.
\end{abstract}

Methods: Thirty-two rats were mechanically ventilated and instrumented to measure mean arterial pressure (MAP) and carotid blood flow (CBF). Animals were bled during 60 minutes in order to maintain MAP at $40 \pm 2 \mathrm{~mm} \mathrm{Hg}$. Ten minutes prior to retransfusion of shed blood, rats randomly received either an intravenous bolus of NaHS $(0.2$ $\mathrm{mg} / \mathrm{kg}$ ) or vehicle $(0.9 \% \mathrm{NaCl})$. At the end of the experiment ( $T=300$ minutes), blood, aorta and heart were harvested for Western blot (inductible Nitric Oxyde Synthase (iNOS), Nuclear factor- $\kappa \mathrm{B}$ (NF- $\kappa \mathrm{B}$ ), phosphorylated Inhibitor $\kappa \mathrm{B}(\mathrm{P}-\mathrm{|} \kappa \mathrm{B})$, Inter-Cellular Adhesion Molecule (I-CAM), Heme oxygenase 1(HO-1), Heme oxygenase 2(HO-2), as well as nuclear respiratory factor 2 (Nrf2)). Nitric oxide $(\mathrm{NO})$ and superoxide anion $\left(\mathrm{O}_{2}{ }^{-}\right)$were also measured by electron paramagnetic resonance.

Results: At the end of the experiment, control rats exhibited a decrease in MAP which was attenuated by NaHS $(65 \pm 32$ versus $101 \pm 17 \mathrm{mmHg}, P<0.05)$. CBF was better maintained in NaHS-treated rats $(1.9 \pm 1.6$ versus $4.4 \pm$ $1.9 \mathrm{ml} /$ minute $P<0.05)$. NaHS significantly limited shock-induced metabolic acidosis. NaHS also prevented iNOS expression and $\mathrm{NO}$ production in the heart and aorta while significantly reducing NF-kB, $\mathrm{P}-\mathrm{l} \kappa \mathrm{B}$ and I-CAM in the aorta. Compared to the control group, $\mathrm{NaHS}$ significantly increased $\mathrm{Nrf} 2, \mathrm{HO}-1$ and $\mathrm{HO}-2$ and limited $\mathrm{O}_{2}{ }^{-}$release in both aorta and heart $(P<0.05)$.

Conclusions: $\mathrm{NaHS}$ is protective against the effects of ischemia reperfusion induced by controlled hemorrhage in rats. NaHS also improves hemodynamics in the early resuscitation phase after hemorrhagic shock, most likely as a result of attenuated oxidative stress. The use of NaHS hence appears promising in limiting the consequences of ischemia reperfusion (IR).

\footnotetext{
* Correspondence: PiAsfar@chu-angers.fr

'Laboratoire HIFIH, UPRES EA 3859, IFR 132, Université d'Angers, Rue Haute

de Reculée, Angers, F-49035 France

Full list of author information is available at the end of the article
} 


\section{Introduction}

Hemorrhagic shock (HS) is a life-threatening complication in both trauma patients and in the operating room $[1,2]$. The pathophysiology of HS is complex, especially during the reperfusion phase [3]. During HS, the state of vasoconstriction turns into vasodilatory shock. According to Landry et al. [4], this phenomenon is related to tissue hypoxia as well as to a proinflammatory immune response [4]. In addition, during the reperfusion phase, cellular injuries induced by ischemia are enhanced, and are associated with excessive production of radical oxygen species (ROS), leading to a further systemic inflammatory response [5].

Hydrogen sulfide $\left(\mathrm{H}_{2} \mathrm{~S}\right)$, is known as an environmental toxic gas [6], but has also recently been recognized as a gasotransmitter [7], similar to nitric oxide (NO) and carbon monoxide $(\mathrm{CO}) . \mathrm{H}_{2} \mathrm{~S}$ is endogenously synthesized [8] and may play a crucial role in critical care according to the recent review of Wagner et al. in 2009 [9]. Depending on the selected models, $\mathrm{H}_{2} \mathrm{~S}$ has been reported to exhibit pro- and anti-inflammatory properties and to display opposite effects in various shock conditions [10-13]. $\mathrm{H}_{2} \mathrm{~S}$ has also been reported to induce direct inhibition of endothelial nitric oxide synthase (eNOS) [14]. However, this effect was linked to the concentration of $\mathrm{H}_{2} \mathrm{~S}$, whereby $\mathrm{H}_{2} \mathrm{~S}$ caused contraction at low doses and relaxation at high doses in both rat and mouse aorta precontracted by phenylephrine [14]. This dual effect was related, at low dosage, to the inhibition of the conversion of citrulline into arginine by eNOS (contraction) and at high dosage by activation of $\mathrm{K}^{+}$ATP channels or due to NO quenching [15]. Blackstone et al. $[10,11]$ recently suggested that inhalation of $\mathrm{H}_{2} \mathrm{~S}$ induced a "suspended animation-like" state which protected animals from lethal hypoxia. Furthermore, Morrison et al. [16] demonstrated that pre-treatment with inhaled or intravenous (i.v.) $\mathrm{H}_{2} \mathrm{~S}$ prevented death and lethal hypoxia in rats subjected to controlled but unresuscitated hemorrhage.

Conversely, Mok et al. [17] reported the hemodynamic effects of the inhibition of $\mathrm{H}_{2} \mathrm{~S}$ synthesis, along with a rapid restoration in mean arterial pressure (MAP) and heart rate (HR), in a model of unresuscitated hemorrhage in rats.

As the vascular effects of $\mathrm{H}_{2} \mathrm{~S}$ are still a matter of debate, and since all of these data originated from unresuscitated hemorrhage, we therefore tested the hypothesis that the $\mathrm{H}_{2} \mathrm{~S}$ donor sodium hydrosulfide (NaHS), infused before retransfusion in a model of a controlled hemorrhagic rat, may improve hemodynamics and attenuate oxidative and nitrosative stresses, as well as the inflammatory response during reperfusion. Since the role of the cardiovascular system during shock becomes critical, we therefore focused on the inflammatory response as well as on the oxidative and nitrosative stresses in the heart and aorta.

\section{Materials and methods}

The animal protocol was approved by the regional animal ethics committee (CREEA-Nantes, France). The experiments were performed in compliance with the European legislation on the use of laboratory animals.

\section{Animals}

Adult male Wistar rats, weighing $325 \pm 15 \mathrm{~g}$, were housed with 12-hour light/dark cycles in the animal facility of the University of Angers (France).

\section{Surgical procedure}

Animals were anesthetized with intraperitoneal pentobarbital (50 mg/kg of body weight) and placed on a homeothermic blanket system in order to maintain rectal temperature between $36.8^{\circ} \mathrm{C}$ and $37.8^{\circ} \mathrm{C}$ throughout the experiment. After local anesthesia with lidocaine $1 \%$ (Lidocaine ${ }^{\circ} 1 \%$ AstraZeneca, Reuil-Malmaison, France), a tracheotomy was performed. Animals were mechanically ventilated (Harvard Rodent 683 ventilator, Harvard Instruments, South Natick, MA, USA) and oxygen was added in order to maintain $\mathrm{PaO}_{2}$ above $100 \mathrm{mmHg}$. The left carotid artery was exposed, and a $2.0 \mathrm{~mm}$ transittime ultrasound flow probe (Transonic Systems Inc., Ithaca, NY, USA) was attached to allow continuous measurement of blood flow (CBF).

After local anesthesia, the femoral artery was canulated both to measure MAP and HR and for the induction of hemorrhagic shock. The homolateral femoral vein was canulated for retransfusion of shed blood, for fluid maintenance and for bolus infusion (either vehicle or NaHS).

\section{Induction of hemorrhagic shock and protocol design}

After a 20-minute stabilization period, controlled hemorrhage [18] was induced by withdrawing approximately $9 \mathrm{ml}$ of blood collected in a heparinized syringe (200 UI) within 10 minutes until MAP decreased to $40 \pm 2 \mathrm{mmHg}$. This state of controlled hemorrhage was maintained during 60 minutes by further blood withdrawal or reinfusion of shed blood. Ten minutes prior to retransfusion time, rats were randomly allocated to receive either NaHS (single i.v. bolus $0.2 \mathrm{mg} / \mathrm{kg}$ body weight) or control (vehicle $0.9 \% \mathrm{NaCl}$ ), and designated as HS-NaHS $(n=11)$ and HS-saline $(n=11)$ respectively. After 60 minutes of shock, shed blood was retransfused within 10 minutes. Animals were continuously monitored for HR, MAP and CBF during 300 minutes. At the end of the experiment, the rats were sacrificed and blood samples were collected for 


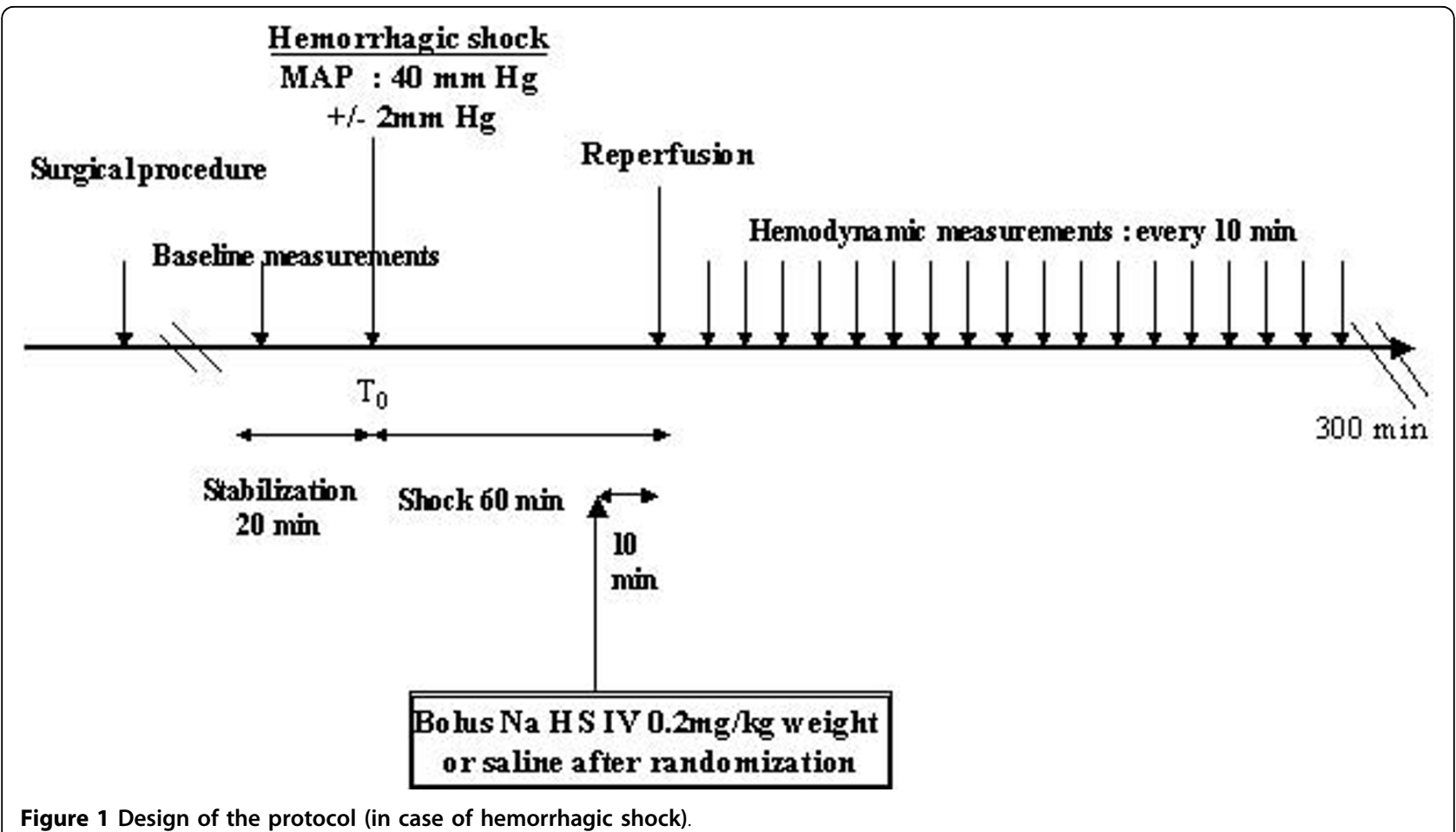

measurement of arterial lactate levels. Aorta and hearts were harvested and maintained in liquid nitrogen for further in vitro analyses (Western blotting, superoxide anion and NO production) (Figure 1).

Two additional groups of rats were managed in the same manner as the other animals but were not bled. One group (control-NaHS, $n=5$ ) received a single bolus of NaHS $(0.2 \mathrm{mg} / \mathrm{kg}$ body weight) while the other group received the vehicle $(0.9 \% \mathrm{NaCl} 0.2 \mathrm{mg} / \mathrm{kg}$ body weight) (control-saline $n=5$ ) in order to assess the hemodynamic effects of NaHS in normal rats.

Maintenance of fluid was performed with a perfusion of $1.2 \mathrm{ml}$ per hour of $0.9 \% \mathrm{NaCl}$ in all groups.

\section{Hydrogen sulfide donor preparation}

The dehydrated NaHS powder (sodium hydrogen sulfide, anhydrous, 2 g, Alpha Aesar GmbH \& Co, UK) was dissolved in isotonic saline under argon gas bubbling, until a concentration of $40 \mathrm{mM}$ was achieved. Intravenous (i.v.) administration was preferred to the inhaled form of $\mathrm{H}_{2} \mathrm{~S}$, as it represented an easier route whilst avoiding side effects such as airway irritation. In accordance with pilot experimentations in our laboratory and a previous study [19], a single intravenous bolus of $\mathrm{NaHS}(0.2 \mathrm{mg} / \mathrm{kg})$ was infused.

\section{Monitoring and measurements}

Arterial blood gases were controlled after the stabilization period in order to adjust mechanical ventilation.
Blood gases, acid-base status and blood glucose were recorded at baseline ( $t=0$ minute), at the end of retransfusion ( $t=70$ minutes) and at the end of the experiment $(t=300$ minutes $)$. MAP, HR, CBF and temperature were recorded during the stabilization period (baseline) and every 10 minutes during the observation period.

\section{In vitro measurements}

Determination by electron paramagnetic resonance (EPR) NO spin trapping

Aorta and heart samples were incubated for 30 minutes in Krebs-Hepes buffer containing: BSA (20.5 g/L), $\mathrm{CaCl}_{2}$ $(3 \mathrm{mM})$ and L-Arginine $(0.8 \mathrm{mM})$. N, N D-Ethyldithiocarbamate and $\mathrm{Fe}^{3}+$ citrate complex (FeDETC) (3.6 mg) and $\mathrm{FeSO}_{4} .7 \mathrm{H}_{2} \mathrm{O}(2.25 \mathrm{mg})$ were separately dissolved under $\mathrm{N}_{2}$ gas bubbling in $10 \mathrm{ml}$ volumes of ice-cold Krebs-Hepes buffer. These compounds were rapidly mixed to obtain a pale yellow-brown opalescent colloid $\mathrm{Fe}(\mathrm{DETC})_{2}$ solution $(0.4 \mathrm{mM})$, which was used immediately. The colloid $\mathrm{Fe}(\mathrm{DETC})_{2}$ solution was added to the organs and incubated for 45 minutes at $37^{\circ} \mathrm{C}$. Thereafter, the organs were snap frozen in plastic tubes using liquid $\mathrm{N}_{2}$. NO measurement was performed on a tabletop $\mathrm{x}$-band spectrometer Miniscope (Magnettech, MS200, Berlin, Germany). Recordings were performed at $77^{\circ} \mathrm{K}$, using a Dewar flask. Instrument settings were: microwave power, $10 \mathrm{~mW}$; amplitude modulation, $1 \mathrm{mT}$; modulation frequency, $100 \mathrm{kHz}$; sweep time, $60 \mathrm{~s}$ 
and number of scans, 5. Levels of NO were expressed as amplitude of signal in unit per weight of dried sample (Amplitude/Wd).

\section{Superoxide anion $\left(\mathrm{O}_{2}^{-}\right)$spin-trapping}

Aorta and heart samples were allowed to equilibrate in deferoxamine-chelated Krebs-Hepes solution containing 1 hydroxy-3methoxycarbonyl 2,2,5,5-tetramethylpyrrolidin $(\mathrm{CMH}$, Noxygen, Germany) $(500 \mu \mathrm{M})$, deferoxamine $(25 \mu \mathrm{M})$ and DETC $(5 \mu \mathrm{M})$ under constant temperature $\left(37^{\circ} \mathrm{C}\right)$ for one hour. The reaction was stopped by placing the samples in ice, subsequently frozen in liquid $\mathrm{N}_{2}$ and analyzed in a Dewar flask by EPR spectroscopy (Magnettech, MS200, Berlin, Germany). The instrument settings were as follows: temperature, $77^{\circ} \mathrm{K}$; microwave power, 1 $\mathrm{mW}$; amplitude modulation, $0.5 \mathrm{mT}$; sweep time, $60 \mathrm{~s}$; field sweep, $60 \mathrm{G}$. Values were expressed in signal amplitude/mg weight of dried tissue (Amplitude/Wd).

\section{Western blotting}

Aorta and heart samples were homogenized in lysis buffer $(0.5 \mathrm{M}$ Tris-HCl, $1.86 \mathrm{~g} / \mathrm{ml}$ EDTA, $1 \mathrm{M} \mathrm{NaCl}, 0.001$ $\mathrm{g} / \mathrm{ml}$ Digitonin, $4 \mathrm{U} / \mathrm{ml}$ Aprotinin, $2 \mu \mathrm{M}$ Leupeptin, $100 \mu \mathrm{M}$ phenylmethylsulfonyl fluoride (PMSF)). Proteins $(20 \mu \mathrm{g})$ were separated on 10\% SDS-PAGE and transferred onto nitrocellulose membranes. Blots were probed by an over-night incubation $\left(4^{\circ} \mathrm{C}\right)$ with a mouse anti-inducible NOS (iNOS) antibody (BD Biosciences, San Jose, CA, USA), a polyclonal rabbit nuclear factor NF-kB p65 antibody (Abcam, Cambridge, UK), a mouse anti-human phosphorylated (ser32/36)-IkB alpha (P-IkBa) antibody (US Biologica, Swampscott, Massachusetts, USA), an anti-rat I-CAM/CD54 antibody (R\&D Systems), a goat COX-1(M-20) antibody (Santa Cruz Biotechnology, Santa Cruz, CA, USA), a goat COX-2 antibody (Santa Cruz Biotechnology), a rabbit polyclonal nuclear respiratory factor Nrf2 (C-20) antibody (Santa Cruz Biotechnology), a rabbit anti-hemeoxygenase-1 (HO-1) polyclonal antibody (Stressgen Bioreagents, San Diego California, USA) or a rabbit anti-heme-oxygenase-2 (HO-2) polyclonal antibody (Stressgen Bioreagents, San Diego California, USA). Membranes were washed and incubated for one hour at room temperature with a secondary anti-mouse, antirabbit or anti-goat peroxidase-conjugated IgG (Promega, Madison, WI, USA).

Blots were visualized using an enhanced chemiluminescence system (ECL Plus; Amersham, Buckinghamshire, $\mathrm{UK})$, after which the membranes were probed again with a polyclonal rabbit anti- $\beta$-actin antibody (Sigma-Aldrich, Saint Quentin Fallavier, France) for densitometric quantification and normalization to $\beta$-actin expression.

\section{Data analysis}

For repeated measurements, one-way analysis of variance was used to evaluate within-group differences. Difference between groups was tested using a two-way analysis of variance (repeated time measurements and treatments as independent variables). When the relevant $\mathrm{F}$ values were significant at the $5 \%$ level, further pairwise comparisons were performed using the Dunnett's test for the effect of time and with Bonferroni's correction for the effects of treatment at specific times. The MannWhitney test was used for inter-group comparisons for Western blotting, $\mathrm{NO}$ and $\mathrm{O}_{2}{ }^{-}$signal measurements. All values are presented as mean \pm SD for $n$ experiments ( $n$ representing the number of animals). All statistics were performed with the Statview software (version 5.0; SAS Institute, Cary, NC, USA). A $P$-value $<0.05$ was considered statistically significant.

\section{Results}

The hydrogen sulfide donor, NaHS, prevents ischemiareperfusion (I/R)-induced hemodynamic dysfunction

There was no significant difference in hemodynamic parameters at baseline (Table 1, Figure 2). Both hemorrhage groups were similarly bled $(9.2 \pm 1.8 \mathrm{~mL}$ versus $9.2 \pm 1.6 \mathrm{~mL}$ for HS-saline and HS-NaHS respectively). While HR was unaffected, MAP and CBF remained significantly decreased after controlled HS despite retransfusion of shed blood, although this effect was significantly $(P<0.05)$ attenuated in HS-NaHS-treated animals (Figure 2). All HS-NaHS-treated animals survived, whereas 5 animals out of 11 died in the HS-saline group within five hours of experimentation from refractory hypotension. The mean survival time in the HS-saline group was $230 \pm 89$ minutes. Arterial pH and base excess were similar at baseline.

Compared to the control group, NaHS significantly limited the decrease in $\mathrm{pH}$ during the reperfusion period $(P<0.05)$ (Table 1). In both control-saline and controlNaHS groups, hemodynamics remained unaltered (MAP, CBF and HR), as was arterial pH. Hence, EPR and Western blot analysis were not performed in these groups.

\section{NaHS prevents I/R-dependent iNOS expression and NO overproduction in cardiovascular tissues}

Compared to the HS-saline group, NaHS treatment in hemorrhagic rats prevented I/R-induced NO overproduction in the aorta and heart $(P<0.05)$ (Figure 3a, c). In agreement with these data, a decreased iNOS protein concentration was found in both aorta and heart in the HS-NaHS group (Figure 3b, d). 
Table 1 Hemodynamic and acid-base measurements

\begin{tabular}{|c|c|c|c|c|}
\hline & Control saline group $(n=5)$ & Control NaHS group $(n=5)$ & HS saline group $(n=11)$ & HS NaHS group $(n=11)$ \\
\hline \multicolumn{5}{|l|}{ MAP $(\mathrm{mmHg})$} \\
\hline Baseline & $145 \pm 8$ & $147 \pm 16$ & $146 \pm 13$ & $140 \pm 12$ \\
\hline Reperfusion & $128 \pm 18$ & $128 \pm 18$ & $131 \pm 16$ & $135 \pm 14$ \\
\hline End experiment & $119 \pm 20$ & $126 \pm 8$ & $65 \pm 32^{\S}$ & $101 \pm 16.5^{* 5}$ \\
\hline \multicolumn{5}{|l|}{ HR (beat/min) } \\
\hline Baseline & $414 \pm 25$ & $402 \pm 55$ & $406 \pm 45$ & $414 \pm 40$ \\
\hline Reperfusion & $408 \pm 34$ & $408 \pm 34$ & $420 \pm 43$ & $398 \pm 45$ \\
\hline End experiment & $414 \pm 25$ & $426 \pm 33$ & $429 \pm 45$ & $423 \pm 57$ \\
\hline \multicolumn{5}{|l|}{ CBF (ml/min) } \\
\hline Baseline & $5.4 \pm 1.1$ & $5.5 \pm 2.3$ & $7.1 \pm 2.7$ & $7.2 \pm 2.3$ \\
\hline Reperfusion & $4.8 \pm 0.7$ & $6.3 \pm 3.5$ & $6.5 \pm 2.9$ & $8.4 \pm 3.5$ \\
\hline End experiment & $4.1 \pm 1.4$ & $7.1 \pm 3.9$ & $1.86 \pm 1.6^{\S}$ & $4.4 \pm 1.9^{* \S}$ \\
\hline \multicolumn{5}{|l|}{$\mathrm{pH}$} \\
\hline Baseline & $7.41 \pm 0.04$ & $7.40 \pm 0.09$ & $7.34 \pm 0.05$ & $7.35 \pm 0.03$ \\
\hline Reperfusion & $7.42 \pm 0.04$ & $7.38 \pm 0.08$ & $7.23 \pm 0.12$ & $7.22 \pm 0.10$ \\
\hline End experiment & $7.40 \pm 0.08$ & $7.41 \pm 0.04$ & $7.27 \pm 0.11$ & $7.34 \pm 0.09 * \$$ \\
\hline \multicolumn{5}{|l|}{ Base excess (mM) } \\
\hline Baseline & $4.56 \pm 1.55$ & $3.76 \pm 1.30$ & $2.41 \pm 1.69$ & $2.98 \pm 1.71$ \\
\hline Reperfusion & $4.96 \pm 2.16$ & $2.82 \pm 1.79$ & $-7.24 \pm 6.7$ & $-3.28 \pm 3.24$ \\
\hline End experiment & $2.60 \pm 1.86$ & $2.14 \pm 2.74$ & $-7.61 \pm 7.23$ & $-2.17 \pm 3.58^{*}$ \\
\hline
\end{tabular}

$M A P$, mean arterial pressure; $\mathrm{HR}$, heart rate; $\mathrm{CBF}$, carotid blood flow.

${ }^{*} P<0.05$ vs. HS saline. ${ }^{\S} P<0.05$ vs. reperfusion.

NaHS reduces I/R-induced up-regulation of cardiovascular phosphorylated $\mathrm{I}-\kappa \mathrm{B}$ and cell adhesion molecules in aorta Compared to the HS-saline group, NaHS significantly decreased $\mathrm{P}-\mathrm{I} \kappa \mathrm{B}$ and protein concentrations in the aorta (Figure $4 \mathrm{a}$ ) and heart (Figure $4 \mathrm{e}$ ) whereas NF- $\kappa \mathrm{B}$ decreased only in the heart (Figure 4d). In addition, HSNaHS treated rats showed a significant decrease in blotting for I-CAM in aorta (Figure 4c) but not in heart $(P<$ 0.05 ) in comparison to the HS-saline group (Figure 4f).

\section{NaHS reduces I/R-induced oxidative stress}

Compared to the HS-saline group, Nrf2 was increased in aorta $(P<0.05)$ (Figure 5a) concomitant with a subsequent increase in $\mathrm{HO}-1$ and $\mathrm{HO}-2$ expressions (Figure $5 b, c)$. However, NaHS did not decrease Nrf2, HO-1 and HO-2 (data not shown) in heart of the HS-NaHS group. Finally, compared to the HS-saline group, NaHS limited $\mathrm{O}_{2}{ }^{-}$release in both tissues $(P<0.05)$ (Figure $5 \mathrm{~d}$, e).

\section{Discussion}

In the present study, we report the beneficial effects of $\mathrm{NaHS}$ as an $\mathrm{H}_{2} \mathrm{~S}$ donor, prior to retransfusion, in a rodent model of controlled hemorrhage. The key findings were that a single i.v. NaHS bolus immediately before retransfusion of shed blood (i) limited the I/R induced-decrease in MAP and (ii) was associated with reduced inflammatory and oxidative stress responses.
Although $\mathrm{H}_{2} \mathrm{~S}$ is usually considered as an endogenous vasodilatator, this effect nevertheless remains a matter of debate. At low concentrations (10 to $100 \mu \mathrm{M} \mathrm{H} \mathrm{H}_{2} \mathrm{~S}$ ), Ali et al. [15] found a vasoconstrictor effect of $\mathrm{H}_{2} \mathrm{~S}$ on rodent aorta, whereas Dombkovski [20] reported that $\mathrm{H}_{2} \mathrm{~S}$ was responsible for either vasodilatation or vasoconstriction, according to species and organ requirements. Furthermore, data reported in the literature are highly conflicting: indeed, Mok et al. [17] reported an increase in MAP in unresuscitated HS treated with $\mathrm{H}_{2} \mathrm{~S}$ synthesis blockers (DL-propargylglycine and $\mu$-cyanoalanine) whereas Morrison et al. [16], using an opposite experimental approach, reported beneficial effects of $\mathrm{H}_{2} \mathrm{~S}$ on survival in rats submitted to lethal unresuscitated HS. In the present study, compared to the HS-saline group, a single $i . v$. bolus of NaHS produced a substantial increase in MAP in hemorrhagic rats. All rats were well oxygenated $\left(\mathrm{PaO}_{2}>100 \mathrm{~mm} \mathrm{Hg}\right.$, data not shown), an observation that was not reported in the studies by Mok et al. [17] and Morrison et al. [16].

The absence of a detrimental effect on stroke volume has already been reported by others $[11,21,22]$. Herein, heart rate was not altered in either group while carotid blood flow was higher in the HS-NaHS group. Since blood flow was decreased in HS-saline, this would suggest a higher stroke volume in HS-NaHS treated rats, although this conclusion could be challenged since cardiac output was not directly measured in this study. 

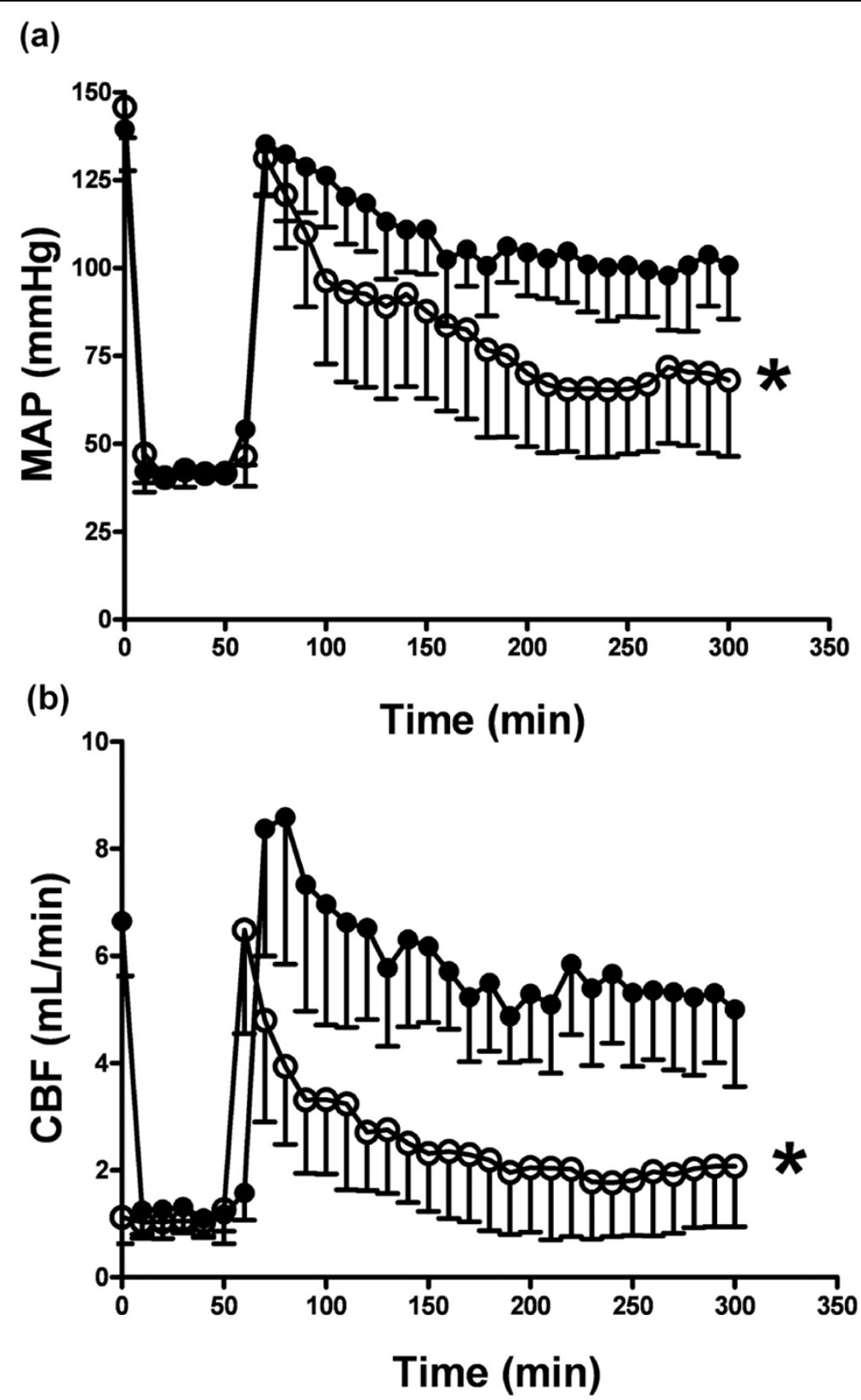

Figure 2 Hemodynamic measurements. Mean arterial blood pressure (MAP) and carotid blood flow (CBF) in hemorrhagic shock (HS)/saline group (white circle) and hemorrhagic shock/NaHS group (black circle) rats recorded during 300 minutes monitoring period. Data are expressed as mean $\pm \mathrm{SD}$ of $n=11$ rats for $\mathrm{HS} / \mathrm{NaHS}$ group, $n=11$ rats for $\mathrm{HS} /$ saline group. ${ }^{*} P<0.05$, significantly different between HS-saline and HSNaHS groups.

Nevertheless, this result is in agreement with improved ejection fraction in a model of myocardial I/R injury [23].

In the present study, NaHS treatment limited the metabolic acidosis induced by I/R. Simon et al. [21] also reported similar metabolic effects in pigs. Whether this effect is due to reduced metabolic demand induced by the sulfide donor or to a direct effect on mitochondrial $\mathrm{K}^{+}{ }_{\text {ATP }}$ channels remains speculative since metabolic rate was not measured.
It is well documented that cardiovascular dysfunction during $I / R$ is partly linked to the activation of the $\mathrm{NF}-\kappa \mathrm{B} /$ Rel pathway. This mechanism has been demonstrated in recent investigations [24], allowing the expression of iNOS and subsequent overproduction of $\mathrm{NO}$ in cardiovascular tissues [25]. As reported by others [26], we show herein that NaHS induced an in vivo downexpression of iNOs, with subsequent decrease in $\mathrm{NO}$ overproduction. 


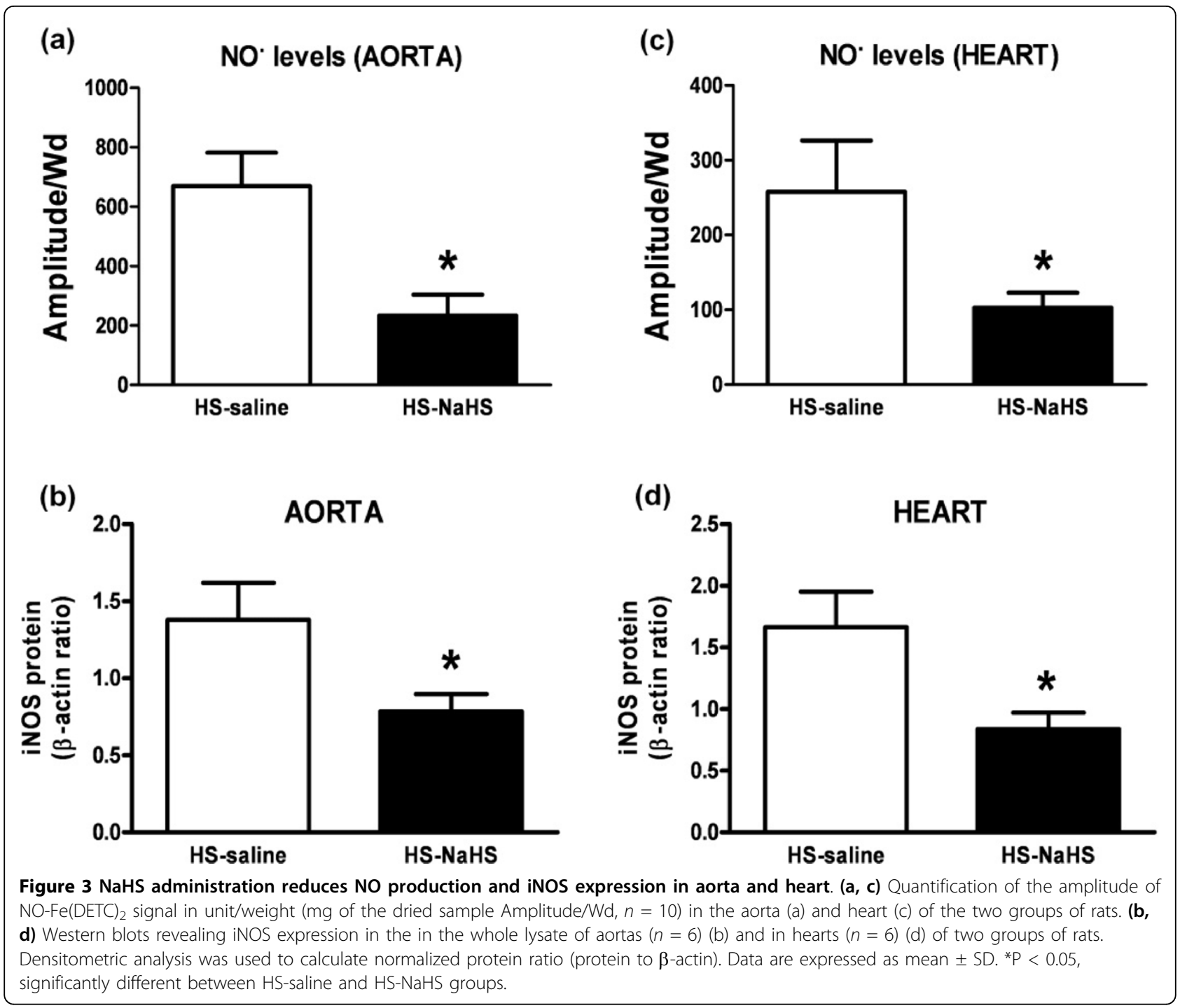

The effects of $\mathrm{H}_{2} \mathrm{~S}$ on inflammation are also a matter of contention $[25,27,28]$. In the present model, we report a predominant inflammatory modulation effect. Indeed, NaHS was found to limit cardiovascular NF- $\kappa \mathrm{B}$ activation as well as decrease I-CAM expression in aorta. These results confirm in vitro experiments which demonstrated that NaHS as well as other $\mathrm{H}_{2} \mathrm{~S}$ endogenous donors modulate leukocyte-mediated inflammation $[25,29]$ by decreasing leukocyte adhesion and leukocyte infiltration [23] through activation of $\mathrm{K}^{+}$ATP channels [25].

In the present study, infusion of a NaHS bolus attenuated oxidative stress induced by $I / R$, as mirrored by a decreased release of $\mathrm{O}_{2}{ }^{-}$in tissues. $\mathrm{H}_{2} \mathrm{~S}$ is known to react with the four different reactive oxygen species [30-32]. Since increased ROS formation is implicated in lipid peroxidation and oxidation of thiol groups, $\mathrm{H}_{2} \mathrm{~S}$, by decreasing ROS overproduction, may in fact limit tissue damage. Our results show that $\mathrm{O}_{2}{ }^{-}$production was decreased in both aorta and heart, suggesting a protective effect on cardiovascular tissues. These results are in agreement with the observations of Sivarajah et al. [33], who recently reported that the cardioprotective effects of NaHS in a model of $I / R$ on isolated cardiomyocytes were related to antioxidative and anti-nitrosative properties.

Nrf2 could contribute to adaptive and cytoprotective responses to various cell damages [31,34]. Different antioxidant cellular pathways are associated with Nrf2 expression such as the heme oxygenase enzymes, HO-1 and HO-2. Indeed, Maines et al. [30] reported increased levels of HO-1 in I/R injuries; moreover, $\mathrm{HO}-1$ was found to improve resistance to oxidative stress [32] and modulate inflammatory response, particularly in hemorrhagic shock [35]. HO-2, meanwhile, is found in almost all tissues and is known as a potential $\mathrm{O}_{2}$ sensor in 


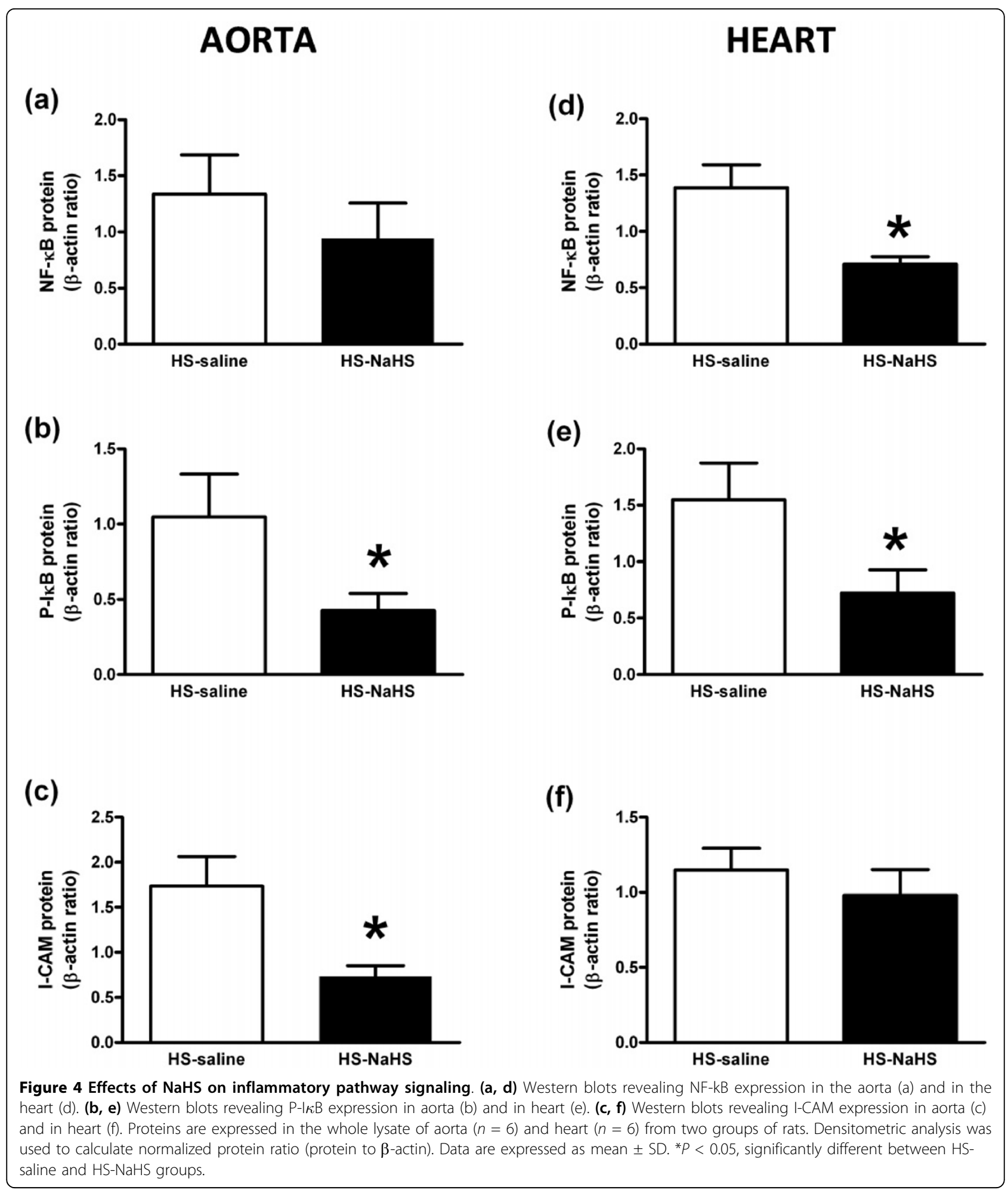

addition to playing a role in the maintenance of vascular tone [32]. Conversely to aortic tissues, there were no changes in Nrf2, HO-1 or HO-2 in the heart samples. In the present experimental design, rats were anesthetized and warmed but not overheated for ethical reasons in accordance with our animal care regulatory agency. The metabolic rate was not measured. In the studies of Blackstone et al. [10,11] and Morisson et al. [16], animals were awake. The difference between the two experimental protocols does not exclude a metabolic 


\section{AORTA}
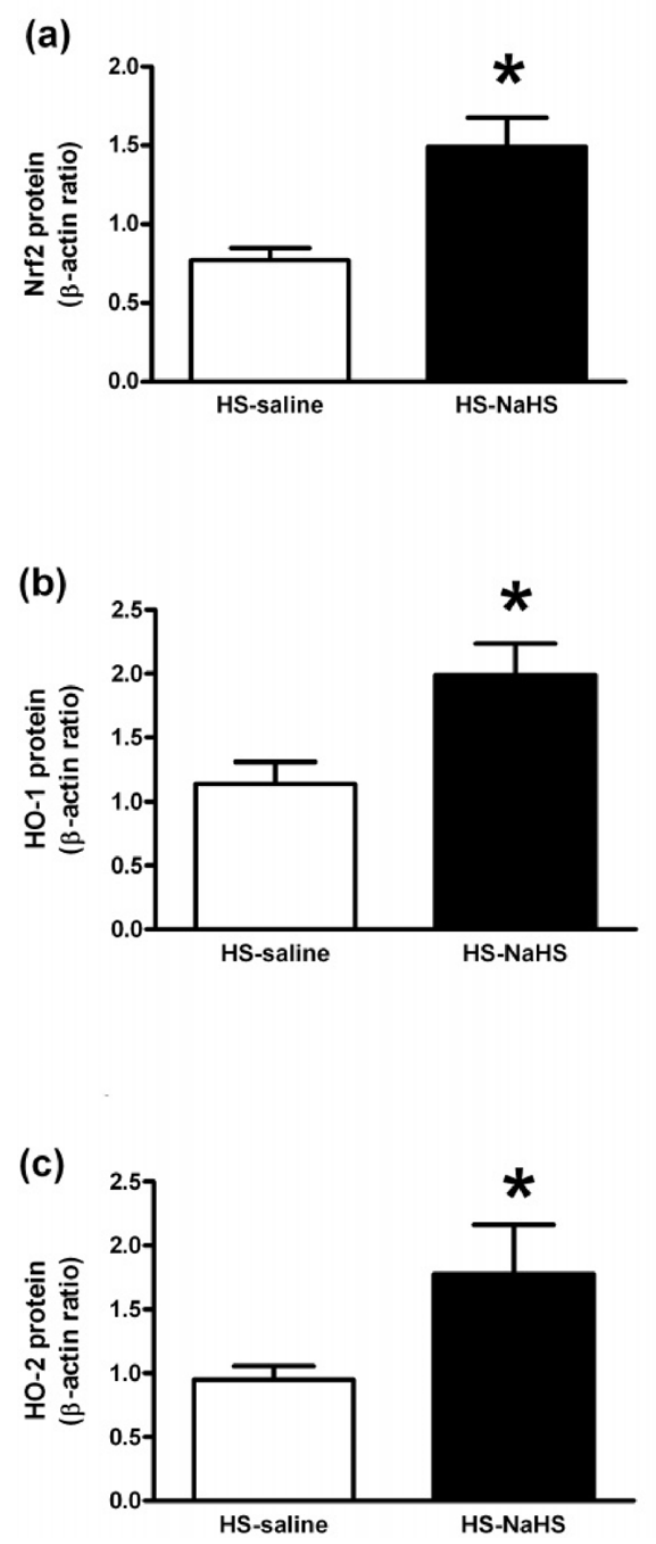

Figure 5 Effects of NaHS on antioxidant pathway. (a, b, c) Western blots revealing in aorta Nrf2 (a), HO-1 (b) and HO-2 (c) in the whole lysate of aortas $(n=6)$. (d, e) Quantification of the amplitude of $\mathrm{O}_{2}{ }^{-}-\mathrm{Fe}(\mathrm{DETC})_{2}$ signal in unit/weight (mg of the dried sample Amplitude/Wd, $n$ $=10$ ) in the aorta (d) and heart (e) of the two groups of rats. Data are expressed as mean \pm SD. ${ }^{*} P<0.05$ and ${ }^{* *} P<0.01$, significantly different between HS-saline and HS-NaHS groups.

effect in our experiments. However, since body temperature remained constant throughout the study period, the putative effect of hypothermia did not significantly contribute to the observed results, which are related to reduced inflammatory and oxidative stress pathways. Consequently, the beneficial effect of NaHS is unlikely the result of a hibernation-like metabolic state of "suspended animation" as reported previously $[10,11,16,22]$. The present observation, however, confirms other studies in which $\mathrm{H}_{2} \mathrm{~S}$ donors $\mathrm{NaHS}$ and $\mathrm{Na}_{2} \mathrm{~S}$ protected against ischemia reperfusion injury [23,33,36-41] and burn injury [29] independently of core temperature.

\section{Study limitations}

The present study has several limitations. By design, in order to mimic a realistic emergency clinical situation, we used a single $i . v$. dose of NaHS. Indeed, given the potential harmful effects of $\mathrm{H}_{2} \mathrm{~S}$ on cytochrome $\mathrm{c}$ and 
the lack of data pertaining to the ideal target dose in the literature, we chose to infuse a single bolus dose of $\mathrm{H}_{2} \mathrm{~S}$. Since a dose-response study was not performed, it is possible that we may have missed toxic or beneficial potential effects of the hydrogen sulfide donor.

Moreover, we did not assess the effects of NaHS on inflammation and oxidative stress in non hemorrhagic rats since the injection of a single dose of $0.2 \mathrm{mg} / \mathrm{kg}$ of NaHS did not alter mean arterial pressure or carotid blood flow. The absence of vascular effects in non hemorrhagic rats may be related to the low infused dose or to the opposite effects of NaHS on isolated arteries. $\mathrm{NaHS}$ has been reported to exert a contractile activity mediated by the inhibition of nitric oxide and endothelial-derived hyperpolarizing factor pathways as well as a relaxation through both $\mathrm{K}^{+}{ }_{\text {ATP }}$ channel-dependent and -independent pathways. In addition, Kubo et al. [14] reported only a very brief and reversible decrease in MAP (100 seconds) after i.v. injection of NaHS at 28 $\mu \mathrm{mol} / \mathrm{kg}$, which is equal to $0.31 \mathrm{mg} / \mathrm{kg}$, a value close to the dose used in the present study. One could speculate that the beneficial effects of NaHS are unveiled in I/R situations when iNOS is up-regulated.

\section{Conclusions}

The present in vivo experimental study of I/R following resuscitated hemorrhagic shock in rats demonstrates that a single i.v. bolus of NaHS limited the decrease in MAP during early reperfusion and down-regulated NF- $\kappa \mathrm{B}$, iNOS and I-CAM expressions. These antiinflammatory effects were associated with decreased $\mathrm{NO}$ and $\mathrm{O}_{2}{ }^{-}$production. Such beneficial effects of $\mathrm{H}_{2} \mathrm{~S}$ donors warrant further experimental studies.

\section{Key messages}

- The results of this in vivo experimental study demonstrate that a single i.v. bolus of hydrogen sulfide (considered as the third gaseous transmitter) donor, NaHS, prevented ischemia reperfusion (I/R)induced hemodynamic dysfunction in a model of controlled hemorrhage in rats.

- NaHS reduced NO production and I/R-dependent iNOS expression and improved metabolic dysfunction.

- NaHS down-regulated NF- $\kappa$ B, iNOS and I-CAM expressions in this model.

- NaHS reduced I/R-induced oxidative stress.

\footnotetext{
Abbreviations

CBF: carotid blood flow; CO: carbon monoxide; eNOS: endothelial nitric oxide synthase; EPR: electron paramagnetic resonance; FeDETC: N, N DEthyldithiocarbamate and $\mathrm{Fe}^{3}+$ citrate complex $\mathrm{HO}-1$ : heme-oxygenase-1; $\mathrm{HO}-2$ : heme-oxygenase-2; HR: heart rate; HS: hemorrhagic shock; $\mathrm{H}_{2} \mathrm{~S}$ : hydrogen sulfide; iNOS: inducible NOS; I/R: ischemia-reperfusion; i.v.: intravenous; MAP: mean arterial pressure; NaHS: sodium hydrosulfide; NO:
}

nitric oxide; Nrf2: nuclear respiratory factor $2 ; \mathrm{O}_{2}$ : superoxide anion; $\mathrm{Pl}-\kappa \mathrm{B}$ : phosphorylated I- $\kappa \mathrm{B}$; PMSF: phenylmethylsulfonyl fluoride; ROS: radical oxygen species; SD: standard deviation.

\section{Acknowledgements}

The authors would like to thank the Association de Recherche en Réanimation Médicale et Médecine Hyperbare (Angers, France) for financial support, P. Legras and J. Roux for animal care, M. Gonnet for NaHS conditioning, and Ph. Lane, C. Hoffmann and P. Pothier for English proofreading.

\section{Author details}

'Laboratoire HIFIH, UPRES EA 3859, IFR 132, Université d'Angers, Rue Haute de Reculée, Angers, F-49035 France. ²Département de Réanimation Médicale et de Médecine Hyperbare, Centre Hospitalo- Universitaire, 4 rue Larrey, Angers, F-49035, France. ${ }^{3}$ INSERM UMR 771; CNRS UMR 6214; Université d'Angers, Rue Haute de Reculée, Angers, F-49035, France. ${ }^{4}$ Sektion Anästhesiologische Pathophysiologie und Verfahrensentwicklung, Klinik für Anästhesiologie, Universitätsklinikum, Parkstrasse 11, Ulm, D-89073, Germany. ${ }^{5}$ Laboratoire de Biophotonique et Pharmacologie, UMR 7213 CNRS, Université de Strasbourg, Faculté de Pharmacie, 74 route du Rhin, Illkirch, F67401, France. ${ }^{6}$ Service de Réanimation Médicale, Nouvel Hôpital Civil. Hôpitaux Universitaires de Strasbourg. 1, place de l'Hôpital, F-67031 Strasbourg, France.

\section{Authors' contributions}

FG participated in the surgical procedure, in in vitro measurements and in the design of the protocol, and drafted the manuscript. MB carried out the Western blotting. MdIB and LF carried out the surgical procedure and in vitro measurements. OD participated in the laboratory investigations. AM, PC and $\mathrm{DH}$ helped to design the study. PR helped to design the study and to draft the manuscript. LL participated in in vitro measurements. PA designed the study, and coordinated and drafted the manuscript. FM participated in the design of the study, performed the statistical analysis and helped to draft the manuscript.

\section{Competing interests}

The authors declare that they have no competing interests.

Received: 10 November 2009 Revised: 15 May 2010

Accepted: 13 September 2010 Published: 13 September 2010

\section{References}

1. Kauvar DS, Lefering $R$, Wade CE: Impact of hemorrhage on trauma outcome: an overview of epidemiology, clinical presentations, and therapeutic considerations. J Trauma 2006, 60:S3-11.

2. Sauaia A, Moore FA, Moore EE, Moser KS, Brennan R, Read RA, Pons PT: Epidemiology of trauma deaths: a reassessment. J Trauma 1995, 38:185-193.

3. Rushing GD, Britt LD: Reperfusion injury after hemorrhage: a collective review. Ann Surg 2008, 247:929-937.

4. Landry DW, Oliver JA: The pathogenesis of vasodilatory shock. N Engl J Med 2001, 345:588-595.

5. Collard CD, Gelman S: Pathophysiology, clinical manifestations, and prevention of ischemia-reperfusion injury. Anesthesiology 2001, 94:1133-1138.

6. Couch L, Martin L, Rankin N: Near death episode after exposure to toxic gases from liquid manure. N Z Med J 2005, 118:U1414.

7. Wang R: Two's company, three's a crowd: can $\mathrm{H}_{2} \mathrm{~S}$ be the third endogenous gaseous transmitter? FASEB J 2002, 16:1792-1798.

8. Lowicka E, Beltowski J: Hydrogen sulfide $\left(\mathrm{H}_{2} \mathrm{~S}\right)$ - the third gas of interest for pharmacologists. Pharmacol Rep 2007, 59:4-24.

9. Wagner F, Asfar P, Calzia E, Radermacher P, Szabo C: Bench-to-bedside review: Hydrogen sulfide - the third gaseous transmitter: applications for critical care. Crit Care 2009, 13:213.

10. Blackstone $\mathrm{E}$, Morrison $\mathrm{M}$, Roth $\mathrm{MB}: \mathrm{H}_{2} \mathrm{~S}$ induces a suspended animationlike state in mice. Science 2005, 308:518.

11. Blackstone $E$, Roth MB: Suspended animation-like state protects mice from lethal hypoxia. Shock 2007, 27:370-372.

12. Szabo C: Hydrogen sulphide and its therapeutic potential. Nat Rev Drug Discov 2007, 6:917-935. 
13. Zhang H, Zhi L, Moore PK, Bhatia M: Role of hydrogen sulfide in cecal ligation and puncture-induced sepsis in the mouse. Am J Physiol Lung Cell Mol Physiol 2006, 290:L1193-L1201.

14. Kubo S, Kurokawa Y, Doe I, Masuko T, Sekiguchi F, Kawabata A: Hydrogen sulfide inhibits activity of three isoforms of recombinant nitric oxide synthase. Toxicology 2007, 241:92-97.

15. Ali MY, Ping CY, Mok YY, Ling L, Whiteman M, Bhatia M, Moore PK: Regulation of vascular nitric oxide in vitro and in vivo; a new role for endogenous hydrogen sulphide? Br J Pharmacol 2006, 149:625-634.

16. Morrison ML, Blackwood JE, Lockett SL, Iwata A, Winn RK, Roth MB: Surviving blood loss using hydrogen sulfide. J Trauma 2008, 65:183-188

17. Mok YY, Atan MS, Yoke PC, Zhong JW, Bhatia M, Moochhala S, Moore PK: Role of hydrogen sulphide in haemorrhagic shock in the rat: protective effect of inhibitors of hydrogen sulphide biosynthesis. Br J Pharmacol 2004, 143:881-889

18. Wiggers C: Present status of shock problem. Physiol Rev 1942, 22:74-123.

19. Meziani F, Kremer H, Tesse A, Baron-Menguy C, Mathien C, Mostefai HA, Carusio N, Schneider F, Asfar P, Andriantsitohaina R: Human serum albumin improves arterial dysfunction during early resuscitation in mouse endotoxic model via reduced oxidative and nitrosative stresses. Am J Pathol 2007, 171:1753-1761.

20. Dombkowski RA, Russell MJ, Schulman AA, Doellman MM, Olson KR: Vertebrate phylogeny of hydrogen sulfide vasoactivity. Am J Physiol Regul Integr Comp Physiol 2005, 288:R243-R252.

21. Koenitzer JR, Isbell TS, Patel HD, Benavides GA, Dickinson DA, Patel RP, Darley-Usmar VM, Lancaster JR Jr, Doeller JE, Kraus DW: Hydrogen sulfide mediates vasoactivity in an $\mathrm{O}_{2}$-dependent manner. Am J Physiol Heart Circ Physiol 2007, 292:H1953-H1960.

22. Simon F, Giudici R, Duy CN, Schelzig H, Oter S, Groger M, Wachter U, Vogt J, Speit G, Szabo C, Radermacher P, Calzia E: Hemodynamic and metabolic effects of hydrogen sulfide during porcine ischemia/ reperfusion injury. Shock 2008, 30:359-364.

23. Volpato GP, Searles R, Yu B, Scherrer-Crosbie M, Bloch KD, Ichinose F, Zapol WM: Inhaled hydrogen sulfide: a rapidly reversible inhibitor of cardiac and metabolic function in the mouse. Anesthesiology 2008, 108:659-668.

24. Elrod JW, Calvert JW, Morrison J, Doeller JE, Kraus DW, Tao L, Jiao X, Scalia R, Kiss L, Szabo C, Kimura H, Chow CW, Lefer DJ: Hydrogen sulfide attenuates myocardial ischemia-reperfusion injury by preservation of mitochondrial function. Proc Natl Acad Sci USA 2007, 104:15560-15565.

25. Oh GS, Pae HO, Lee BS, Kim BN, Kim JM, Kim HR, Jeon SB, Jeon WK Chae HJ, Chung HT: Hydrogen sulfide inhibits nitric oxide production and nuclear factor-kappaB via heme oxygenase-1 expression in RAW264.7 macrophages stimulated with lipopolysaccharide. Free Radic Biol Med 2006, 41:106-119.

26. Zanardo RC, Brancaleone V, Distrutti E, Fiorucci S, Cirino G, Wallace JL: Hydrogen sulfide is an endogenous modulator of leukocyte-mediated inflammation. FASEB J 2006, 20:2118-2120.

27. Kubo S, Doe I, Kurokawa Y, Nishikawa H, Kawabata A: Direct inhibition of endothelial nitric oxide synthase by hydrogen sulfide: contribution to dual modulation of vascular tension. Toxicology 2007, 232:138-146

28. Jeong SO, Pae HO, Oh GS, Jeong GS, Lee BS, Lee S, Kim DY, Rhew HY, Lee KM, Chung HT: Hydrogen sulfide potentiates interleukin-1 $\beta$-induced nitric oxide production via enhancement of extracellular signalregulated kinase activation in rat vascular smooth muscle cells. Biochem Biophys Res Commun 2006, 345:938-944

29. Li L, Whiteman M, Guan YY, Neo KL, Cheng Y, Lee SW, Zhao Y, Baskar R, Tan CH, Moore PK: Characterization of a novel, water-soluble hydrogen sulfide-releasing molecule (GYY4137): new insights into the biology of hydrogen sulfide. Circulation 2008, 117:2351-2360.

30. Esechie A, Kiss L, Olah G, Horvath EM, Hawkins H, Szabo C, Traber DL: Protective effect of hydrogen sulfide in a murine model of acute lung injury induced by combined burn and smoke inhalation. Clin Sci (Lond) 2008, 115:91-97.

31. Maines MD, Mayer RD, Ewing JF, McCoubrey WK Jr: Induction of kidney heme oxygenase-1 (HSP32) mRNA and protein by ischemia/reperfusion: possible role of heme as both promotor of tissue damage and regulator of HSP32. J Pharmacol Exp Ther 1993, 264:457-462.

32. Scarpulla RC: Transcriptional paradigms in mammalian mitochondrial biogenesis and function. Physiol Rev 2008, 88:611-638.
33. Wagener FA, Volk HD, Willis D, Abraham NG, Soares MP, Adema GJ, Figdor CG: Different faces of the heme-heme oxygenase system in inflammation. Pharmacol Rev 2003, 55:551-571.

34. Sivarajah $\mathrm{A}$, Collino $\mathrm{M}$, Yasin $\mathrm{M}$, Benetti $\mathrm{E}$, Gallicchio M, Mazzon $\mathrm{E}$, Cuzzocrea S, Fantozzi R, Thiemermann C: Anti-apoptotic and antiinflammatory effects of hydrogen sulfide in a rat model of regional myocardial I/R. Shock 2009, 31:267-274.

35. Huang HC, Nguyen T, Pickett CB: Phosphorylation of Nrf2 at Ser-40 by protein kinase $C$ regulates antioxidant response element-mediated transcription. J Biol Chem 2002, 277:42769-42774.

36. Tamion F, Richard V, Bonmarchand G, Leroy J, Lebreton JP, Thuillez C: Induction of heme-oxygenase-1 prevents the systemic responses to hemorrhagic shock. Am J Respir Crit Care Med 2001, 164:1933-1938.

37. Tripatara P, Sa PN, Collino M, Gallicchio M, Kieswich J, Castiglia S, Benetti E, Stewart KN, Brown PA, Yaqoob MM, Fantozzi R, Thiemermann C: Generation of endogenous hydrogen sulfide by cystathionine- $\gamma$-lyase limits renal ischemia/reperfusion injury and dysfunction. Lab Invest 2008, 88:1038-1048.

38. Patel NS, Brancaleone V, Renshaw D, Rocha J, Sepodes B, Mota-Filipe $H$, Perretti M, Thiemermann C: Characterisation of cystathionine gammalyase/hydrogen sulphide pathway in ischaemia/reperfusion injury of the mouse kidney: an in vivo study. Eur J Pharmacol 2009, 606:205-209.

39. Sivarajah $A, M c D o n a l d ~ M C$, Thiemermann C: The production of hydrogen sulfide limits myocardial ischemia and reperfusion injury and contributes to the cardioprotective effects of preconditioning with endotoxin, but not ischemia in the rat. Shock 2006, 26:154-161.

40. Jha S, Calvert JW, Duranski MR, Ramachandran A, Lefer DJ: Hydrogen sulfide attenuates hepatic ischemia-reperfusion injury: role of antioxidant and antiapoptotic signaling. Am J Physiol Heart Circ Physiol 2008, 295:H801-H806.

41. Sodha NR, Clements RT, Feng J, Liu Y, Bianchi C, Horvath EM, Szabó C, Sellke FW: The effects of therapeutic sulfide on myocardial apoptosis in response to ischemia-reperfusion injury. Eur I Cardiothorac Surg 2008, 33:906-913.

\section{doi:10.1186/cc9257}

Cite this article as: Ganster et al: Effects of hydrogen sulfide on hemodynamics, inflammatory response and oxidative stress during resuscitated hemorrhagic shock in rats. Critical Care 2010 14:R165.

\section{Submit your next manuscript to BioMed Central and take full advantage of:}

- Convenient online submission

- Thorough peer review

- No space constraints or color figure charges

- Immediate publication on acceptance

- Inclusion in PubMed, CAS, Scopus and Google Scholar

- Research which is freely available for redistribution

Submit your manuscript at www.biomedcentral.com/submit
Ciomed Central 